\title{
CONHECIMENTO E INSTRUMENTALIZAÇÃO DE PROFESSORES SOBRE DESENVOLVIMENTO DE FALA: AÇÕES DE PROMOÇÃO DA SAÚDE
}

\section{Knowledge and instrumentation of teachers on speech development: actions for health promotion}

\author{
Lílian Marinho dos Santos ${ }^{(1)}$, Amélia Augusta de Lima Friche (2), Stela Maris Aguiar Lemos ${ }^{(3)}$
}

\begin{abstract}
RESUMO
Objetivos: verificar o conhecimento de educadores infantis sobre desenvolvimento de fala e descrever uma ação fonoaudiológica de instrumentalização. Método: o estudo foi realizado em duas escolas públicas de educação infantil de Belo Horizonte. Foram elaborados e aplicados os instrumentos: Mapa de Fala; Escala de Avaliação da Estratégia e Questão Aberta. Os Mapas de Fala e a Escala de Avaliação da Estratégia foram preenchidos pelos professores pré e pós-instrumentalização; a Questão Aberta foi respondida pós-instrumentalização. Entre as etapas foi realizada uma instrumentalização aos professores abordando o desenvolvimento de fala, informações sobre como identificar crianças com alterações de fala, quando encaminhá-las ao fonoaudiólogo e como estimular a fala correta em sala de aula. A amostra foi composta por 5 professores de alunos de 4 e 5 anos. Resultados: os fonemas que sofreram maiores modificações quanto à ocorrência, indicando melhora na percepção dos professores pós-instrumentalização foram: /p/, / / /, / / /, c/l/v e c/r/v. Houve na percepção dos educadores uma redução do índice de inadequação de fala, comparando pré e pós-instrumentalização (37\% para 4,4\%), o que demonstra que a instrumentalização modificou a percepção dos professores sobre a fala dos alunos. Os professores relataram que a instrumentalização os auxiliaram na identificação da normalidade e dos problemas de fala das crianças. Conclusão: a instrumentalização acerca do desenvolvimento de fala, realizada por fonoaudiólogos, é uma ação que contribui para prevenção e promoção da saúde auxiliando a prática docente dos professores.
\end{abstract}

DESCRITORES: Capacitação; Educação Infantil; Fala; Promoção da Saúde; Saúde Pública

\section{INTRODUÇÃO}

A atuação do fonoaudiólogo nas escolas tem contribuído para inserção de ações de prevenção e promoção da saúde no âmbito escolar. Cabe ressaltar que no período escolar e em especial na

(1) Fonoaudióloga graduada pela Universidade Federal de Minas Gerais.

(2) Mestre em Saúde Pública pela Universidade Federal de Minas Gerais; Professora Assistente do Curso de Fonoaudiologia da Universidade Federal de Minas Gerais, Belo Horizonte, Minas Gerais, Brasil.

(3) Doutora em Ciências pelo programa de Distúrbios da Comunicação Humana UNIFESP; Professora Adjunto do Curso de Fonoaudiologia da Universidade Federal de Minas Gerais, Belo Horizonte, Minas Gerais, Brasil.

Conflito de interesses: inexistente fase da educação infantil a criança passa por intenso desenvolvimento da comunicação humana. Um dos grandes marcos do desenvolvimento comunicativo nesta população é a aquisição e desenvolvimento da fala, e dos aspectos fonológicos.

A fala é um ato motor que expressa a linguagem e seus órgãos articuladores são a laringe, faringe, palato mole e duro, língua, dentes, bochechas, lábios e fossas nasais. Para que esta função seja realizada da maneira correta, são necessários controle motor central e harmonia no funcionamento dos articuladores. A aquisição do sistema fonológico faz parte do processo de desenvolvimento da linguagem da criança e envolve a percepção e produção correta dos sons verbais ${ }^{1}$.

A aquisição fonológica normal ocorre quando, dentro de uma determinada faixa etária 
(aproximadamente dos quatro aos seis anos de idade), o domínio do sistema fonológico da língua-alvo é atingido espontaneamente em uma sequência comum à maior parte das crianças. Ainda que a construção do sistema fonológico ocorra de maneira semelhante para todas as crianças, variações individuais são evidenciadas entre elas. A variação é percebida tanto no domínio segmental quanto prosódico, dentro das etapas e características gerais do desenvolvimento, encontradas em todas as crianças ${ }^{2}$.

No desenvolvimento de fala, observa-se uma hierarquia na ocorrência dos fonemas de acordo com as faixas etárias e habilidades motoras específicas para esta função ${ }^{3,4}$. De 2 anos e 6 meses a 3 anos e 6 meses encontra-se a ocorrência dos fonemas $/ \mathrm{m} /, / \mathrm{n} /, / \mathrm{p} /, / \mathrm{b} /, / \mathrm{t} /, / \mathrm{d} /$, /f/, /v/, /k/, /l/, /s/, $/ \mathrm{z} /, / 3 /, / \mathrm{g} /, / \mathrm{h} /, / \mathrm{x} /, / \mathrm{N} /, / \mathrm{S} /$ e $\{\mathrm{S}\}$. Entre 3 anos e 6 meses e 4 anos e 6 meses verifica-se a ocorrência dos fonemas acima citados, mais o /R/, encontros consonantais com o fonema /// e o $\{R\}$. Entre 4 anos e 6 meses e 5 anos e 6 meses acrescenta-se o encontro consonantal com o fonema /r/ aos demais já citados ${ }^{3,4}$.

A posição que determinado fonema ocupa na palavra é um fator a se considerar na aquisição destes, pois se sabe que a posição de onset simples é a de mais fácil aquisição, seguida da coda e, por fim, do onset complexo². No Português Brasileiro (PB), a aquisição fonológica mostra padrões definidos de domínio dos segmentos (vogais >> plosivas, nasais >> fricativas $>>$ líquidas) e das estruturas silábicas $(\mathrm{CV}, \mathrm{V}>>\mathrm{CVV}>>\mathrm{CVC}>>\mathrm{CCV}){ }^{5}$.

$O$ período de maior aquisição dos fonemas é entre 2 a 2 anos e 6 meses. Aos 4 anos aproximadamente $75 \%$ das consoantes são produzidas adequadamente e aos 6 anos 97\% delas são faladas corretamente ${ }^{4}$.

No âmbito escolar diversos estudos ${ }^{6-9}$ foram desenvolvidos buscando estabelecer um perfil de desenvolvimento fonológico e/ou estimar a prevalência de alterações de fala na população de crianças e adolescentes.

Um estudo dedicado a identificar alterações de fala em escolares ${ }^{6}$, especialmente alterações de fala em crianças da faixa etária de 4 a 11 anos, revelou que há uma prevalência de $63,64 \%$ para os desvios fonológicos, $31,82 \%$ para os desvios fonético-fonológicos e $4,54 \%$ dos casos referentes aos desvios puramente fonéticos. Dentre os desvios fonológicos mais encontrados estão a redução de encontro consonantal, o apagamento de líquida não lateral e o apagamento de líquida intervocálica não lateral.

Outro estudo, realizado em oito cidades do Vale do Paraíba, demonstrou que $8,27 \%$ das crianças de 7 anos da amostra apresentaram alteração fonológica e destas $77 \%$ eram do sexo masculino. Os dados mostraram que os processos mais utilizados em meninos foram simplificação de encontro consonantal, seguido de simplificação de líquida; nas meninas ocorreram o ensurdecimento de fricativas e a simplificação de encontro consonantal ${ }^{7}$.

Com um grupo de crianças com idade entre 4 anos e 9 meses e 6 anos e 9 meses da cidade de Belo Horizonte foi realizado um estudo, a fim de descrever diferentes aspectos do desenvolvimento fonológico. Os autores verificaram que $63,2 \%$ da amostra apresentaram alterações fonéticas e/ ou fonológicas. Os processos fonológicos mais comuns foram: substituição de consoantes líquidas $(30,5 \%)$, redução de encontro consonantal $(25,3 \%)$, apagamento de consoante líquida no final de sílaba $(21,1 \%)$ e dessonorização. Não houve diferença estatisticamente significante entre as crianças do segundo período com as crianças do terceiro período, mas o índice de densidade fonológica foi maior entre as crianças mais novas do que entre as mais velhas ${ }^{8}$.

Em crianças da primeira série do ensino fundamental, observou-se em outro estudo que a prevalência de desordens de fala em crianças é de $24,6 \%$, o que demonstra um grande problema de saúde infantil. A faixa etária de maior é prevalência é até os cinco anos e a menor é aos 7 anos. A ocorrência de alteração de fala foi maior em meninos e a escolaridade dos pais influencia numa relação inversamente proporcional essas alterações. Observou-se, também, que a maioria das desordens de comunicação afeta as crianças na fase em que estas estão interiorizando os conceitos humanos e a linguagem, o que é motivo de preocupação, pois as alterações nessa fase comprometem o desenvolvimento global das crianças. Assim, esse fato merece destaque para os governos implantarem medidas preventivas e de detecção precoce a fim de diminuir as comorbidades ${ }^{9}$.

As alterações de fala em nível fonológico afetam a organização lingüística dos sons, fazendo com que os mesmos não sejam usados contrastivamente. Isso, por sua vez, acarretará dificuldades na compreensão do que está sendo dito ${ }^{10}$.

Todas as questões supracitadas devem ser discutidas na educação infantil buscando subsidiar ações pedagógicas e fonoaudiológicas neste espaço.

Dada a relevância que as instituições infantis apresentam para o desenvolvimento global das crianças, por proporcionarem riqueza de estímulos, torna-se importante a atuação fonoaudiológica privilegiando ações de prevenção e promoção da saúde ${ }^{11}$. 
Entende-se que a Promoção da Saúde é uma das estratégias de produção da saúde, cuja especificidade é o fortalecimento da abordagem dos determinantes sociais nas ações do setor, potencializando formas mais amplas de pensar e trabaIhar junto aos sujeitos e às comunidades. Nessa direção, as ações de Promoção da Saúde tomam como foco os modos de viver de sujeitos e comunidades, entendendo que estes não se referem ao exercício da vontade e/ou liberdade individual e comunitária ${ }^{12}$.

A atuação do fonoaudiólogo em escolas de educação infantil deve estar voltada à demanda da comunidade e ser realizada em parceria com os educadores. Essa parceria busca desenvolver ações de prevenção e promoção da saúde e favorecer o desenvolvimento da criança. Com as informações fornecidas pelo profissional da saúde, os professores, profissionais que permanecem a maior parte do tempo com as crianças no dia-adia, adquirem conhecimento suficiente para propor medidas de estimulação, identificar alterações e realizar encaminhamentos. Sendo assim, a atuação fonoaudiológica em escolas de educação infantil deve favorecer o desenvolvimento das habilidades comunicativas por meio de ações promotoras de saúde e preventivas com as próprias crianças, professores e demais funcionários ${ }^{13}$.

A fim de se verificar a eficácia da orientação de professores de educação infantil realizada por meio de periódicos mensais, foi realizado um trabalho na zona Oeste da cidade de São Paulo em 23 préescolas com 104 professores voluntários. Estas escolas participavam do Programa Fono na Escola no qual havia distribuição de periódicos mensais sobre temas fonoaudiológicos visando instrumentalizar o professor e contribuir em sua prática na sala de aula. Os informativos eram distribuídos na última semana de cada mês na seguinte ordem: outubro de 2005 sobre Atraso de Linguagem e Novembro do mesmo ano sobre Distúrbio Articulatório. Foi aplicado um questionário com questões abertas aos professores antes e após a divulgação dos informativos. As autoras concluíram que a implementação de informativos foi eficaz, contribuindo para melhora nas respostas ao final do programa. Observou-se também que os professores têm formação específica para atuar na área da educação, necessitando assim de informações complementares acerca do desenvolvimento e alterações de linguagem e fala ${ }^{14}$.

Na perspectiva atual de Escolas Promotoras de Saúde, a escola de educação infantil deve ser um local educacional e de promoção da saúde, que visa desenvolver ações saudáveis, preventivas e educativas no ambiente escolar ${ }^{15}$.
Um estudo realizado em uma escola de educação infantil em Fortaleza, Ceará, no período de 2002 a 2003, teve como objetivo descrever o trabalho de promoção da saúde desenvolvido nesta escola. Foram utilizados para a coleta de dados uma entrevista semi-estruturada com sete pessoas que trabalham na escola: equipe pedagógica e equipe do núcleo de saúde. A análise dos dados identificou categorias importantes, tais como: "1) o cuidar como elemento presente no trabalho de promoção da saúde na educação infantil, 2) a importância da formação de hábitos de higiene por meio do trabalho educativo; 3) promoção da saúde na escola utilizando a Pedagogia de Projetos; e 4) a relação afetiva entre os profissionais de saúde e os alunos, como elemento de sustento para o trabalho como a promoção de saúde na escola". Foi constatada a importância da iniciativa dos educadores da escola pesquisada em trabalhar com a promoção da saúde e que ocorreu uma responsabilização dos profissionais da saúde em realizar este trabalho. Tendo em vista a necessidade de integração de profissionais da saúde e equipe pedagógica, as autoras perceberam a importância de revisar as propostas curriculares dos centros de formação e conscientizar esses profissionais a fim de melhorar o desenvolvimento compartilhado de atividades comuns ${ }^{16}$.

Um trabalho desenvolvido em uma Unidade Municipal de Educação Infantil (UMEI) do município de Belo Horizonte em 2007 constatou que os profissionais da educação, têm conhecimentos básicos a respeito da aquisição e desenvolvimento de linguagem e dos distúrbios da comunicação humana e que esses mesmos profissionais conhecem a Fonoaudiologia atuando na escola apenas do ponto de vista clínico e preventivo. O estudo também aponta que as oficinas com os temas sobre audição e voz, desenvolvidas na UMEI, se mostraram eficientes na capacitação dos educadores no que diz respeito ao desenvolvimento de ações de promoção e prevenção da saúde em Fonoaudiologia ${ }^{17}$.

A educação infantil, em muitos estados do país, está desprovida de políticas públicas ou apresenta uma precariedade destas. A gestão permanece centralizada e investindo pouco na prática de formação continuada dos educadores, o que acarreta em profissionais despreparados para atenderem as demandas pedagógicas, assistenciais e de cuidados das crianças. Torna-se necessário então a instituição de políticas públicas urgentes para a educação infantil ${ }^{18}$.

Os professores de educação infantil em sua maioria percebem que os cuidados e ações neste estabelecimento podem contribuir para a 
prevenção de acidentes e promoção da saúde, mas muitas vezes não tem conhecimento suficiente para desenvolver atividades que abordem isso. Sendo os educadores infantis as pessoas que lidam dia-a-dia com as crianças na nas escolas de educação infantil, percebe-se a necessidade de prepará-las sobre o processo saúde-doença, para tanto é necessário abordar a temática desde a sua formação ${ }^{19}$.

O presente estudo justifica-se pela importância do trabalho fonoaudiológico voltado para ações coletivas e intersetoriais, que integrem as áreas de saúde e educação, na construção coletiva do saber, capacitando os educadores e propiciando sua formação como agentes multiplicadores de ações promotoras da saúde em Fonoaudiologia.

Os objetivos deste estudo foram: i) verificar o conhecimento dos professores acerca do desenvolvimento de fala de crianças de 4 e 5 anos de duas escolas públicas de educação infantil, levantado a partir de uma ação de promoção da saúde; ii) caracterizar o desenvolvimento de fala dos alunos observados pelos professores quanto à adequação pré e pós-instrumentalização; iii) avaliar a estratégia utilizada e iv) analisar a aceitação dos professores frente às atividades propostas pré e pós-instrumentalização.

\section{MÉTODO}

\section{Delineamento do estudo}

Trata-se de estudo descritivo, do tipo caso, com amostra de conveniência composta por educadores de ensino infantil de duas escolas de educação infantil do município de Belo Horizonte. A primeira escola se localiza na região Nordeste do município e conta com 82 crianças de 0 a 6 anos e a segunda escola localiza-se na região Leste do mesmo município e conta com 170 crianças de 0 a 6 anos.

A seleção e recrutamento dos sujeitos da pesquisa constaram dos seguintes critérios:

- Critérios de inclusão: ser professor de educação infantil de alunos na faixa etária de 4 a 5 anos de idade e ler, concordar com e assinar o Termo de Consentimento Livre e Esclarecido.

- Critérios de exclusão: recusar-se ou desistir de participar da pesquisa, preenchimento incompleto ou não preenchimento dos Mapas de Fala, da Escala de Avaliação da Estratégia utilizada e da questão aberta.

Para coleta de dados foram elaborados e aplicados os seguintes instrumentos:

1. Mapa de Fala - gráfico ilustrativo contendo todos os fonemas do português do Brasil, ou seja, os sons produzidos por falantes da língua portuguesa (figura 1). Este mapa foi elaborado com base na literatura da área ${ }^{3}$. O professor tinha três opções para preenchimento do mapa: colorir a casela correspondente ao fonema de verde quando este era produzido sempre (sistemático) pelo aluno, de amarelo quando era produzido às vezes (assistemático) e de vermelho quando o fonema nunca era produzido.

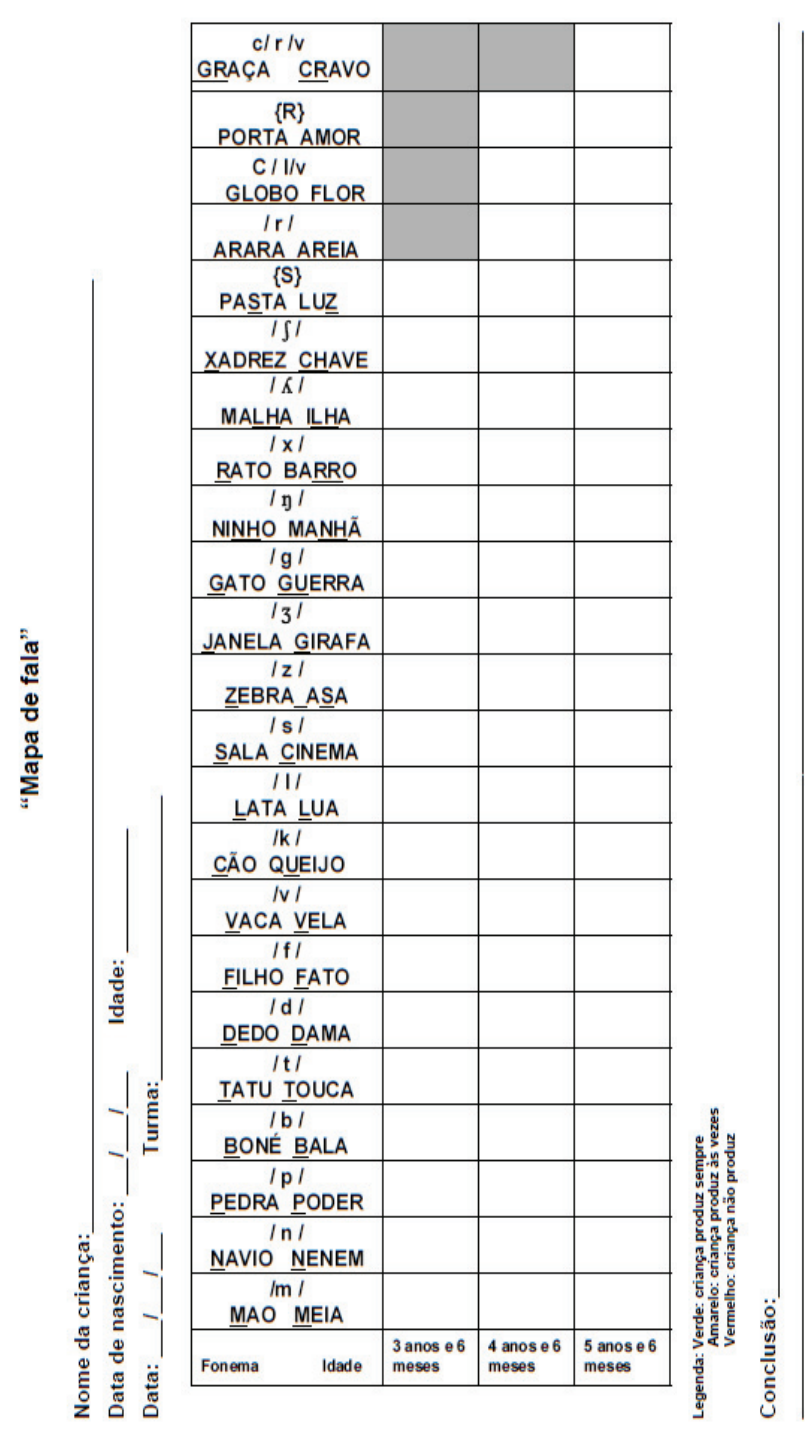

Figura 1 - Mapa de Fala

2. Escala de Avaliação da Estratégia - formulário de avaliação da estratégia realizada contendo as opções: excelente, bom, regular, pobre, ruim, incapaz de responder, em que o professor foi orientado a assinalar apenas uma opção.

3. Questão aberta - esta foi utilizada para avaliar o impacto da estratégia e a eficácia da instrumentalização na prática docente. Pergunta: Você acredita que o treinamento contribuiu para sua prática docente? 
Para realização da pesquisa foram seguidas quatro etapas, a saber:

Etapa 1: seleção e recrutamento da amostra. Foram selecionados indivíduos adultos, professores de educação infantil de alunos na faixa etária de 4 a 5 anos de idade de duas escolas de educação infantil do município de Belo Horizonte. Esses sujeitos foram recrutados por meio de reunião na escola, para exposição do projeto e suas finalidades. Após o projeto ter sido aceito, os professores leram e assinaram o Termo de Consentimento Livre e Esclarecido.

Etapa 2: preenchimento dos Mapas de Fala préinstrumentalização e da Escala de Avaliação da Estratégia. Os professores foram orientados individualmente em seu horário de trabalho nas respectivas escolas, quanto ao preenchimento dos Mapas de Fala de seus alunos e da Escala de Avaliação da Estratégia. Para tanto, eles receberam a quantidade de Mapas de Fala suficiente de acordo com o número de alunos e a Escala de Avaliação da Estratégia. Neste momento do estudo, ao preencher a Escala de Avaliação, o professor avaliava o instrumento Mapa de Fala.

Etapa 3: instrumentalização dos professores. Foi elaborado um roteiro com os eixos temáticos: desenvolvimento de fala normal, desvios fonológicos, desvios fonéticos e medidas de promoção da saúde e prevenção, que incluíram informações aos professores sobre como identificar crianças com alterações de fala, quando encaminhá-las ao fonoaudiólogo e como estimular a fala correta em sala de aula. Realizou-se a atividade em reunião com cada professor, em que os temas foram apresentados em exposição dialogada.

Etapa 4: preenchimento dos Mapas de Fala pós-instrumentalização, da Escala de Avaliação da Estratégia e da Questão Aberta. Os professores preencheram novamente os Mapas de Fala dos mesmos alunos observados na pré- instrumentalização, a Escala de Avaliação da Estratégia e a Questão Aberta. Estando as Escalas e os Mapas de Fala preenchidos, foram analisados os resultados encontrados tendo como referência o padrão de normalidade proposto pela literatura ${ }^{3}$, caracterizouse o desenvolvimento de fala dos alunos observados pelos professores e verificou-se a eficácia da instrumentalização. Em seguida, foram discutidos individualmente com cada professor os resultados e elaborado juntamente com eles o Perfil de Desenvolvimento de Fala das respectivas turmas. Foi fornecido também aos professores um folder sobre o Desenvolvimento de Fala.

A presente pesquisa foi aprovada, sob o parecer $\mathrm{n}^{\circ} 410 / 08$, pelo Comitê de Ética em Pesquisa da Universidade Federal de Minas Gerais - COEP/UFMG.

\section{Caracterização da Amostra}

A amostra do estudo foi composta por 5 educadores, todos do sexo feminino, responsáveis por 58 alunos das turmas de segundo e terceiro período de educação infantil.

Inicialmente, pré-instrumentalização, os professores preencheram um corpus de 58 Mapas de Fala; no segundo momento, pós-instrumentalização, preencheram somente 46 Mapas de Fala. Assim sendo, 12 Mapas de Fala preenchidos préinstrumentalização foram excluídos do estudo.

\section{Análise de dados}

Realizou-se análise descritiva e comparativa dos Mapas de Fala e das Escalas de Avaliação da Estratégia, considerando-se os resultados obtidos pré e pós-instrumentalização das professoras. Analisou-se a produção dos fonemas de cada Mapa de Fala $(n=46)$ para se alcançar a caracterização coletiva do desenvolvimento de fala dos alunos.

Optou-se por classificar e agrupar os fonemas com produção sistemática e assistemática no critério de ocorrência e a ausência de produção foi classificada como não-ocorrência.

Para caracterização do perfil do desenvolvimento de fala dos alunos (amostra total), de acordo com os professores, foi verificada a concordância no preenchimento dos Mapas de Fala pré e pósinstrumentalização de cada fonema por meio da estatística kappa. Esta é uma medida de concordância usada em escalas nominais que fornece uma idéia do quanto as observações se afastam das esperadas, fruto do acaso, indicando assim o quão legítimas são as interpretações. Assim, ao analisar os valores de kappa foi utilizado, como referência, a classificação dos resultados da estatística kappa discutida pela literatura ${ }^{20}$. O valor de kappa de 0,80 a 1,00 foi classificado como concordância excelente, de 0,61 a 0,80, como concordância boa, de 0,41 a 0,60 como concordância moderada, de 0,21 a 0,40 como concordância razoável e de 0,20 a 1,00 como concordância pobre. Considerou-se estatisticamente significante $o$ valor de $p$ menor ou igual a 0,05.

Após a análise da concordância do preenchimento por fonemas, realizou-se o levantamento da ocorrência em percentual de cada fonema pré e pós-instrumentalização, tendo com referência a descrição de ocorrência dos fonemas proposta por Mourão et $\mathrm{al}^{3}$. Feito isso, a ocorrência dos fonemas pré e pós-instrumentalização foi analisada por sexo e faixa etária. Nesta análise consideraram-se como tendo produção adequada as crianças que produziram todos os fonemas esperados para sua faixa etária e como tendo produção inadequada as crianças que não produziram um ou mais fonemas que seriam esperados para sua faixa etária. 
Para análise da Escala de Avaliação da Estratégia também se utilizou a estatística kappa, a fim de estabelecer o nível de concordância em seu preenchimento pré e pós-instrumentalização pelos professores.

Foi realizada, ainda, a análise dos dados obtidos por meio da Questão Aberta. A análise de dados foi fundamentada na Análise de Conteúdo ${ }^{21}$, de tal modo que as idéias centrais das respostas de uma mesma questão foram identificadas para posterior comparação do grupo e síntese do conhecimento geral. Após a seleção das categorias a serem analisadas em cada questão, verificou-se a sua freqüência de ocorrência (aparecimento) nos discursos dos sujeitos.

A entrada, o processamento e a análise quantitativa dos dados foram realizados por meio do programa EPI-INFO, versão 3.4 (2007).

\section{RESULTADOS}

Os resultados das análises quantitativas e qualitativas são apresentados em duas partes; na Parte I apresenta-se a caracterização da amostra e o conhecimento do professor expresso nos Mapas de Fala (pré e pós-instrumentalização) e na Parte II apresenta-se a avaliação da estratégia de promoção da saúde realizada.

\section{Parte I - Caracterização da Amostra e Conhecimento dos Professores}

$\mathrm{Na}$ Figura 2 tem-se a distribuição do corpus de Mapa de Fala por sexo e faixa etária pré e pós-instrumentalização.

Na Figura 3 destaca-se a distribuição do corpus por escola e sexo pré e pós- instrumentalização.

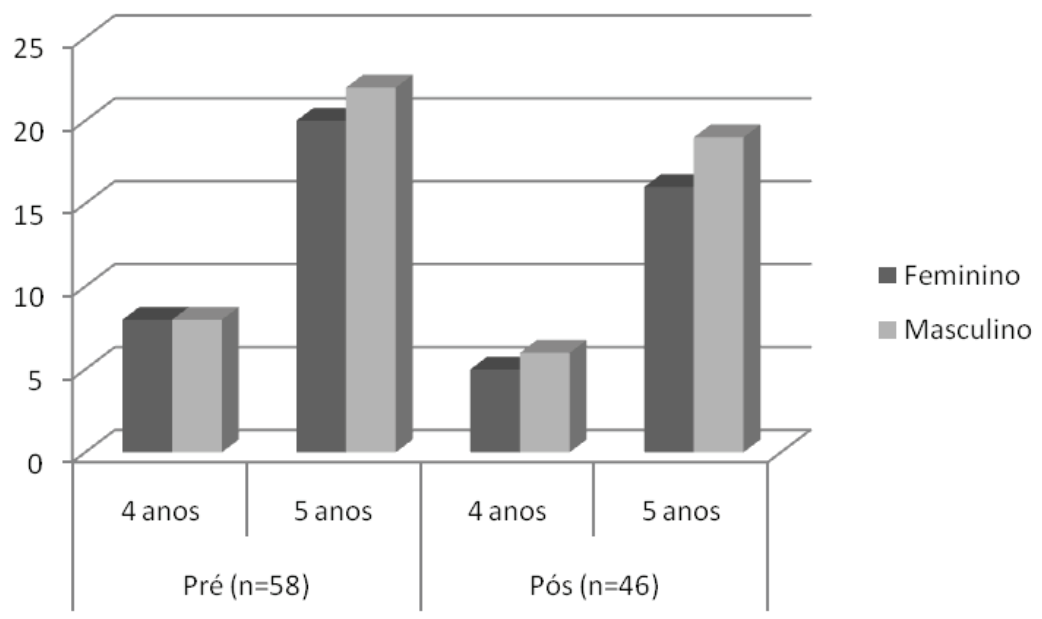

Figura 2 - Gráfico Demonstrativo da distribuição do corpus de Mapa de Fala por sexo e faixa etária pré e pós- instrumentalização

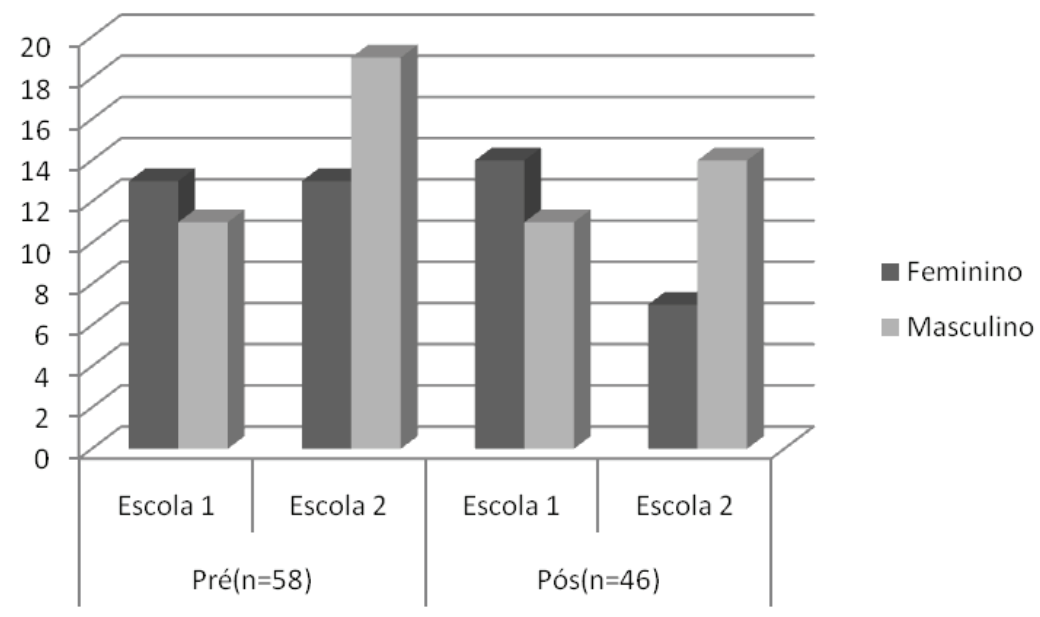

Figura 3 - Gráfico Demonstrativo da distribuição do corpus por escola e sexo pré e pós- instrumentalização 
Na Figura 4 está apresentado a distribuição da ocorrência e das medidas estatísticas identificandose os fonemas da amostra total.
$\mathrm{Na}$ Tabela 1 mostra-se a distribuição da ocorrência dos fonemas por faixa etária e sexo da amostra total.

\begin{tabular}{|c|c|c|c|c|}
\hline \multirow[b]{2}{*}{ Fonema } & \multicolumn{2}{|c|}{ Ocorrência do Fonema*** (\%) } & \multicolumn{2}{|c|}{ Concordância } \\
\hline & $\begin{array}{c}\text { Pré- } \\
\text { instrumentalização }\end{array}$ & $\begin{array}{c}\text { Pós- } \\
\text { instrumentalização }\end{array}$ & $\begin{array}{c}\text { Pré e Pós- } \\
\text { Instrumentalização } \\
\text { kappa* }^{*}\end{array}$ & $\begin{array}{l}\text { Classificação da } \\
\text { concordância* }\end{array}$ \\
\hline$/ \mathrm{m} /$ & 97,8 & 97,8 & $1,00^{\star *}$ & Excelente \\
\hline$/ \mathrm{n} /$ & 95,6 & 97,8 & $0,66^{\star *}$ & Boa \\
\hline$/ p /$ & 84,8 & 97,8 & $0,22^{* *}$ & Razoável \\
\hline /b/ & 93,5 & 97,8 & $0,48^{\star *}$ & Moderada \\
\hline /f/ & 93,5 & 95,6 & $1.00^{* *}$ & Excelente \\
\hline$/ \mathrm{v} /$ & 95,6 & 95,6 & $1.00^{\star *}$ & Excelente \\
\hline$/ \mathrm{t} /$ & 95,6 & 97,8 & $0,66^{\star \star}$ & Boa \\
\hline$/ d /$ & 93,5 & 97,8 & $1,00^{\star *}$ & Excelente \\
\hline /s/ & 91,3 & 95,6 & $0,79^{* *}$ & Boa \\
\hline$|z|$ & 91,3 & 95,6 & $0,65^{\star *}$ & Boa \\
\hline /l/ & 95,6 & 95,6 & $1.00^{\star *}$ & Excelente \\
\hline$/ \mathrm{r} /$ & 84,8 & 95,6 & $0,40^{* *}$ & Razoável \\
\hline /S/ & 91,3 & 93,5 & $0,65^{\star *}$ & Boa \\
\hline$|3|$ & 95,6 & 95,6 & $1.00^{* *}$ & Excelente \\
\hline$/ K /$ & 89,1 & 95,6 & $0,65^{\star *}$ & Boa \\
\hline$/ \mathrm{y} /$ & 93,5 & 97,8 & $0,48^{* *}$ & Moderada \\
\hline$/ \mathrm{k} /$ & 95,6 & 97,8 & $0,65^{\star *}$ & Boa \\
\hline$/ g /$ & 93,5 & 95,6 & $0,79^{* *}$ & Boa \\
\hline$|x|$ & 95,6 & 97,8 & $0,66^{\star *}$ & Boa \\
\hline$\{S\}$ & 93,5 & 95,6 & $0,79^{* *}$ & Boa \\
\hline$\{\mathrm{R}\}$ & 93,5 & 95,6 & $0,79^{\star *}$ & Boa \\
\hline$c / l / v$ & 78,3 & 95,6 & $0,28^{\star *}$ & Razoável \\
\hline $\begin{array}{c}c / r / v \\
(n=28)\end{array}$ & 89,3 & 96,4 & $0,47^{\star *}$ & Moderada \\
\hline
\end{tabular}

Legenda: *Valores da estatística kappa (ALTMAN, 1991)

**resultados com nível de significância $\mathrm{p} \leq 0,05$

${ }^{* * * A}$ Análise da ocorrência dos fonemas baseada em Mourão,1994

Figura 4 - Distribuição da ocorrência e das medidas estatísticas por fonemas da amostra total (n=46) 
Tabela 1 - Distribuição da ocorrência dos fonemas por faixa etária e sexo da amostra total

\begin{tabular}{|c|c|c|c|c|c|c|c|c|c|c|c|c|c|c|c|c|}
\hline \multirow{5}{*}{ Sexo } & \multicolumn{16}{|c|}{ Ocorrência dos Fonemas } \\
\hline & \multicolumn{8}{|c|}{ Pré-instrumentalização } & \multicolumn{8}{|c|}{ Pós-instrumentalização } \\
\hline & \multicolumn{4}{|c|}{ Feminino } & \multicolumn{4}{|c|}{ Masculino } & \multicolumn{4}{|c|}{ Feminino } & \multicolumn{4}{|c|}{ Masculino } \\
\hline & \multicolumn{2}{|c|}{ Adequado } & \multicolumn{2}{|c|}{ Inadequado } & \multicolumn{2}{|c|}{ Adequado } & \multicolumn{2}{|c|}{ Inadequado } & \multicolumn{2}{|c|}{ Adequado } & \multicolumn{2}{|c|}{ Inadequado } & \multicolumn{2}{|c|}{ Adequado } & \multicolumn{2}{|c|}{ Inadequado } \\
\hline & $\mathbf{n}$ & $\%$ & $\mathbf{n}$ & $\%$ & $\mathbf{n}$ & $\%$ & $\mathbf{n}$ & $\%$ & $\mathbf{n}$ & $\%$ & $\mathbf{n}$ & $\%$ & $\mathbf{n}$ & $\%$ & $\mathbf{n}$ & $\%$ \\
\hline 4 anos & 1 & 2,2 & 4 & 8,7 & 1 & 2,2 & 5 & 10,9 & 5 & 10,9 & - & - & 5 & 10,9 & 1 & 2,2 \\
\hline 5 anos & 14 & 30,4 & 2 & 4,3 & 13 & 28,3 & 6 & 13,0 & 16 & 34,8 & - & - & 18 & 39,1 & 1 & 2,2 \\
\hline Total & 15 & 32,6 & 6 & 13,0 & 14 & 30,4 & 11 & 23,9 & 21 & 45,6 & - & - & 23 & 50 & 2 & 4,4 \\
\hline
\end{tabular}

Legenda: *Análise da ocorrência dos fonemas baseada em Mourão,1994

\section{Parte II - Análise das ações desenvolvidas}

$\mathrm{Na}$ Figura 5 destaca-se a distribuição da avaliação das estratégias pré e pós instrumentalização pelos professores
Na Figura 6 encontram-se expostas as respostas das professoras à pergunta: Você acredita que o treinamento contribuiu para sua prática docente?

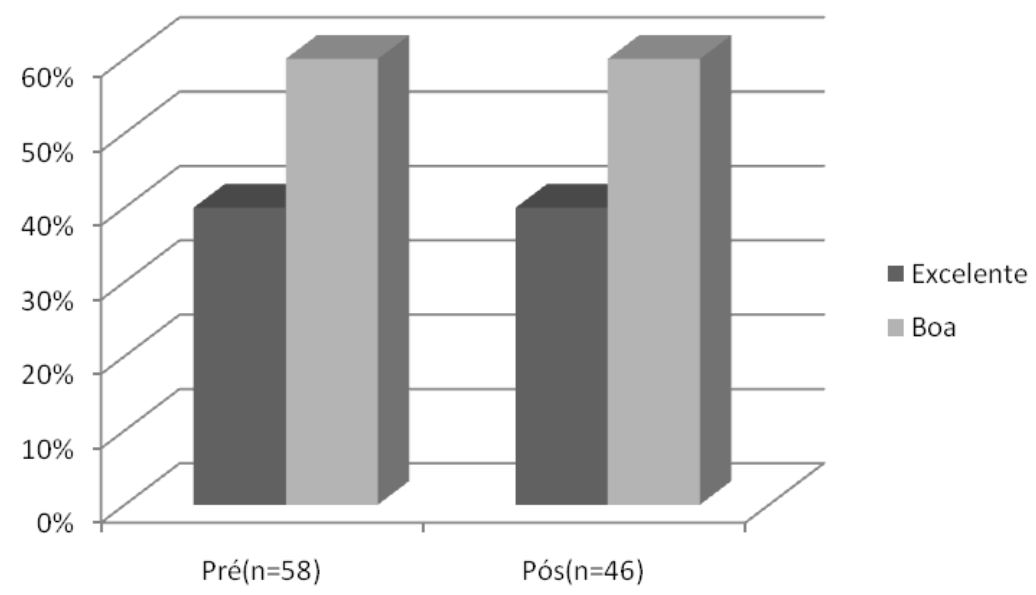

Figura 5 - Gráfico Demonstrativo da distribuição da avaliação das estratégias pré e pós instrumentalização pelos professores

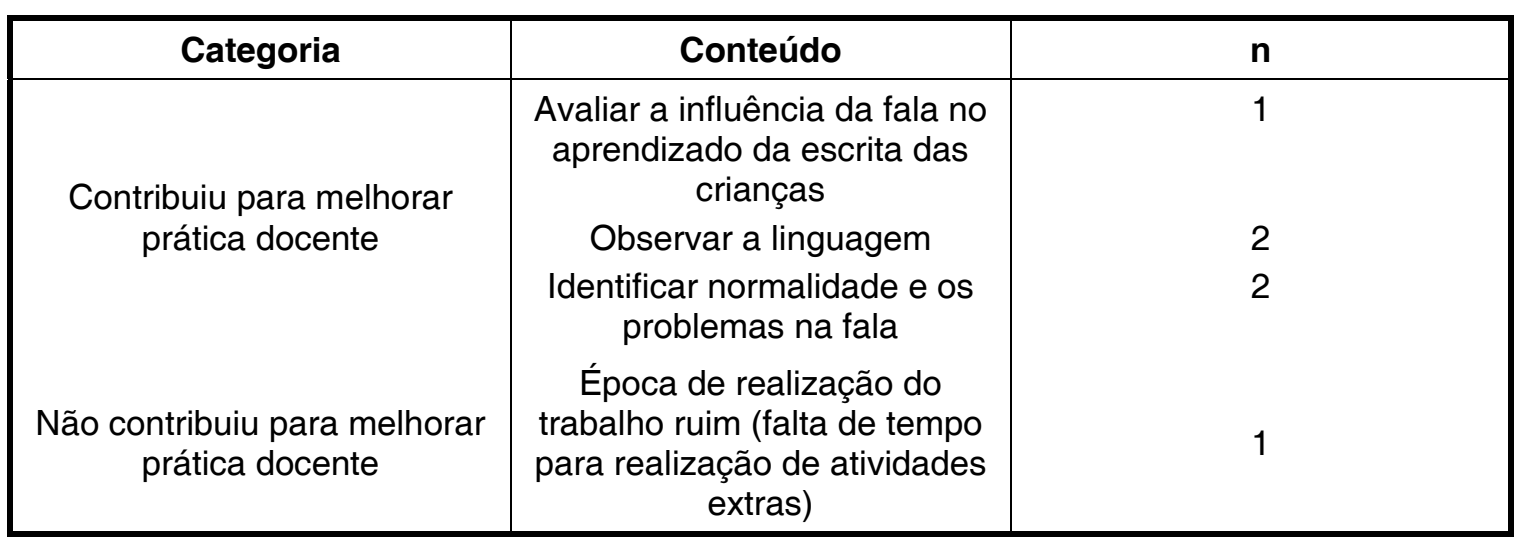

Legenda: $\mathrm{n}=$ número de sujeitos

Figura 6 - Distribuição das respostas dos sujeitos à pergunta: Você acredita que o treinamento contribuiu para sua prática docente 


\section{DISCUSSÃO}

A amostra do estudo foi composta por maior número de crianças do sexo masculino e na faixa etária de 5 anos (Figura 2).

Verificou-se diminuição no número de Mapas de Fala preenchidos pós-instrumentalização, principalmente na escola 2, em crianças de ambos os sexos. Este fato - menor nível de adesão dos professores desta escola - pode estar relacionado à falta de tempo e disponibilidade dos professores no momento da realização da pesquisa (Figura 3). Tal fato (pouca adesão, por baixa disponibilidade dos sujeitos pesquisados), encontra eco em outro estudo 22 voltado para "instrumentalização de professores".

Ao analisar os dados, do corpus total de Mapas de Fala (Figura 4), foi verificado que para a maioria dos fonemas houve concordância - excelente ou boa - pré e pós-instrumentalização, evidenciando que os preenchimentos pré e pós-instrumentalização foram bastante semelhantes, não sofrendo influência da instrumentalização. Este resultado não corrobora com a literatura compilada ${ }^{17}$. Do nosso ponto de vista, esses dados podem ser devido à faixa etária das crianças da amostra, uma vez que nesta fase já se espera um inventário fonológico praticamente completo. Por outro lado, a análise da ocorrência de alguns fonemas /n/, /p/, /b/, /f/, /t/, $/ \mathrm{d} /, / \mathrm{s} /, / \mathrm{z} /, / \mathrm{s} /, / \mathrm{S} /, / \mathrm{N} /, / \mathrm{h} / / \mathrm{k} /, / \mathrm{g} /, / \mathrm{x} /,\{\mathrm{S}\},\{\mathrm{R}\}$, bem como das combinações $\mathrm{c} / \mathrm{l} / \mathrm{v}$ e $\mathrm{c} / \mathrm{r} / \mathrm{v}$ revelou que a capacitação proporcionou melhor percepção dos professores sobre a fala dos alunos, uma vez que a ocorrência aumentou pós-instrumentalização, o que significa que a capacitação foi eficaz para melhorar a percepção dos fonemas pelas professoras ${ }^{14}$.

Outro dado relevante, diz respeito à maior modificação quanto à ocorrência pré e pós-instrumentalização dos seguintes fonemas: /p/, / $/ /, / r /$, c/l/v e $\mathrm{c} / \mathrm{r} / \mathrm{v}$.

De acordo com a literatura compulsada ${ }^{23}$ é mais difícil identificar plosivas não-vozeadas, pois na produção destas o ouvinte tende a perceber o fonema como vozeado, o que corrobora os achados do nosso estudo quanto à baixa ocorrência do fonema /p/ pré-instrumentalização.

A dificuldade na percepção do / / e / / / pode estar relacionada com a influência que as vogais têm na facilitação da produção ${ }^{24,25}$. Outro fator também pode ser o fato destes fonemas serem um dos últimos a serem adquiridos do inventário fonológico das crianças ${ }^{26}$ No que diz respeito aos encontros consonantais $\mathrm{c} / \mathrm{l} / \mathrm{v}$ e $\mathrm{c} / \mathrm{r} / \mathrm{v}$, podemos considerar a dificuldade na percepção encontrada no estudo, devido a estes serem as últimas estruturas a alcançar estabilidade dentro do sistema fonológico da criança, principalmente devido à complexidade da estrutura silábica CCV, que envolve um controle motor fino na articulação. Conforme indica a literatura ${ }^{27,28}$.

A baixa ocorrência dos encontros consonantais e/ou omissões destes na fala dos alunos são comuns em crianças da faixa etária da amostra do estudo $^{6,8}$. Estes dados sugerem que a princípio, no momento da pré-instrumentalização, houve indicação de atraso no desenvolvimento de fala dos alunos, uma vez que de acordo com a literatura estes fonemas ou a maioria destes já deveriam ter sido adquiridos ${ }^{3,4}$. No entanto, a análise do preenchimento pós-instrumentalização não evidenciou presença de alterações no desenvolvimento de fala.

É válido ressaltar que a baixa ocorrência dos fonemas poderia estar relacionada à dificuldade de percepção dos fonemas pelos professores e/ou à alteração de fala do aluno propriamente dita. Considerando que as ocorrências dos fonemas $/ \mathrm{p} /, / \mathcal{N} /$, $/ \mathrm{r} / \mathrm{c} \mathrm{c} / \mathrm{l} / \mathrm{v}$ e c/r/v aumentaram pós-instrumentalização, destaca-se que as professoras realmente modificaram suas percepções em relação à fala de seus alunos.

O valor de $p$ indicou significância estatística na análise de concordância do preenchimento pré e pós-instrumentalização para todos os fonemas. Assim, há evidência de que os resultados encontrados não aconteceram somente ao acaso, demonstrando que as professoras preencheram os Mapas de Fala observando a emissão dos alunos.

$\mathrm{Na}$ análise da tabela 1 , observou-se que préinstrumentalização as crianças de 4 anos do sexo feminino e 5 anos do sexo masculino tiveram maior índice de inadequação. Já pós-instrumentalização, todas as crianças do sexo feminino, seja de 4 ou 5 anos, estavam adequadas. Foi observado um índice de $4,4 \%$ de inadequação do sexo masculino, demonstrando que após a capacitação dos professores permaneceu a inadequação da fala nas crianças deste sexo. Estes dados corroboram com outros estudos que evidenciaram que a faixa etária de maior prevalência de desordens da fala é em torno dos cinco anos e acontece principalmente no sexo masculino ${ }^{7,9}$.

Houve grande dificuldade na análise do encontro consonantal $\mathrm{c} / \mathrm{r} / \mathrm{v}$, pois o preenchimento deste fonema em muitos casos foi realizado de forma incorreta, uma vez que no Mapa de Fala as professoras só deveriam preencher a ocorrência ou não deste fonema nos alunos acima de 5 anos, pois de acordo com a literatura não é esperado a ocorrência deste fonema em crianças de 4 anos ${ }^{3}$. Em muitos casos as professoras deixaram de preencher o fonema mesmo em crianças de 5 anos, o que reduziu em grandes proporções os dados 
sobre este fonema, impossibilitando assim uma análise fidedigna.

Quanto à avaliação da estratégia, observou-se (Figura 5) que $40 \%$ dos sujeitos classificaram a estratégia utilizada neste estudo como excelente e $60 \%$ classificaram como boa, o que demonstra que a atuação fonoaudiológica foi bem aceita pelos educadores. A reflexão sobre medidas de prevenção e promoção da saúde acerca do desenvolvimento de fala, assim como a capacitação auxiliam os professores a perceber melhor a fala de seus alunos, é de suma importância que essa estratégia seja implementada nas políticas públicas de saúde e de educação ${ }^{13,15}$.

No que se refere às respostas dos educadores à Questão Aberta (Figura 6) verificaram-se relatos de que a instrumentalização contribuiu para a prática docente. As professoras 1, 2 e 3 relataram que "aprenderam a identificar a normalidade $e$ os problemas de fala e aprenderam a observar a linguagem de seus alunos", o professor 4 relatou que "aprendeu a avaliar a influência da fala no aprendizado da escrita". A professora 5 relatou que a instrumentalização não contribuiu para melhorar a prática docente, devido à falta de tempo para realização de atividades extra-escolares. Estes dados mostram que é possível e necessário contribuir com os educadores por meio de parcerias com outros profissionais e/ou mudanças curriculares (na formação de pedagogos), para que possam conhecer mais acerca do desenvolvimento global, incluindo a fala e a linguagem. Dados semelhantes foram encontrados em outros estudos ${ }^{16,18}$. A literatura compulsada indicou que os professores necessitam de capacitação e apoio para atuar como agentes promotores de saúde ${ }^{29}$.

No presente estudo foram verificadas limitações, tais como: tamanho da amostra, controle da adesão do professor, limitação do Mapa de Fala devido às constantes atualizações da teoria fonológica e a não existência de uma avaliação do fonoaudiólogo para confirmação dos resultados que foram obtidos por meio da percepção dos educadores sobre o desenvolvimento de fala de seus alunos.

Foi possível verificar que os educadores possuíam algum conhecimento em relação ao desenvolvimento de fala e seus distúrbios. No entanto, verificou-se que eles nunca tinham vivenciado programas de treinamento e instrumentalização a respeito de tal assunto. Observou-se, ainda assim, que o processo de instrumentalização proporcionado aos educadores contribuiu para ampliar o conhecimento destes em relação ao desenvolvimento de fala de seus alunos e à importância do desenvolvimento de medidas de prevenção e promoção da saúde nas escolas Em outras palavras, este estudo se revelou como uma possibilidade do professor otimizar a observação de seus alunos e a encaminhá-los quando necessário à avaliação fonoaudiológica.

\section{CONCLUSÕES}

Para a maioria dos fonemas, a classificação da concordância pré e pós-instrumentalização foi excelente ou boa, não sofrendo influência da instrumentalização. Os fonemas que sofreram maiores modificações quanto à ocorrência, indicando melhora na percepção pós-instrumentalização foram: $/ p /, / \mathbb{N} /$, $/ \mathrm{r} / \mathrm{c} / \mathrm{l} / \mathrm{v}$ e c/r/v.

Verificou-se $4,4 \%$ das crianças pós-instrumentalização apresentaram inadequação de fala e todas eram do sexo masculino. Assim a redução do índice de inadequação de fala comparando pré e pósinstrumentalização (37\% para 4,4\%) demonstra que a capacitação modificou a percepção dos educadores sobre a fala dos alunos.

A maioria dos professores envolvidos no estudo avaliou positivamente a estratégia utilizada. Os professores relataram que a capacitação contribuiu na prática docente, pois os auxiliaram na observação da linguagem e na identificação da normalidade e dos problemas de fala das crianças.

\section{AGRADECIMENTOS}

Às escolas de educação infantil e professores, pela disponibilidade em participar deste estudo e permitir a produção deste conhecimento. 


\section{ABSTRACT}

Purpose: to check the knowledge of children educators about speech development and describe an speech therapy instrumentation action. Method: the study was conducted in two public schools of kindergarten at Belo Horizonte. We developed and applied the following tools: Map Speech; Rating Scale Strategy and Open Issues. Maps and Speech Strategy Rating Scale were completed by teachers before and after instrumentation; the Open Question post-instrumentation answered. Between steps we performed an instrumentation development for the teachers covering speech, information on how to identify children with speech disorders, when to refer them to the speech therapist and how to stimulate the right speech in the classroom. The sample consisted of five teachers for students from 4 to 5 year old. Results: phonemes that have suffered major changes in the occurrence, indicating an improvement in the perception of teachers after instrumentation were:/p/, / $/ \mathrm{l}, / \mathrm{r} / \mathrm{c} / \mathrm{c} / \mathrm{v}$ e $\mathrm{c} / \mathrm{r} / \mathrm{v}$. There was a perception of educators in reducing rates of inappropriate speech, comparing pre-and postinstrumentation (37\% to $4.4 \%$ ), which shows that the instrumentation has changed the perception of teachers on the students' speech. Teachers reported that the instrumentation assisted in the identification of normal and speech problems of children. Conclusion: the instrumentation for the development of speech, performed by speech therapists, is a measure that contributes for prevention and health promotion aiding the teaching practice of the teachers.

KEYWORDS: Training; Childhood Education; Speech; Health Promotion; Public Health

\section{REFERÊNCIAS}

1. Marchesan IQ. Alterações de fala de origem músculo esquelética. In: Ferreira LP, Befi-Lopes DM, Limongi SCO. Tratado de fonoaudiologia.1a edição. São Paulo: Roca; 2004. p- 292-303.

2. Lamprecht RR. Aquisição fonológica do Português: perfil de desenvolvimento e subsídios para a terapia. Porto Alegre: Artmed; 2004.

3. Mourão LF, Parlato EM, Silvério KCA, Altmann EBC, Chiari BM. Descrição da ocorrência dos fonemas da língua portuguesa em pré-escolares. Pró-Fono Revista de Atualização Científica. 1994; 6(1): 27-32.

4. Santini CRQS. Aquisição Fonológica de Crianças de 2:0 a 6:11 falantes do Português. In: Marchesan IQ, Zorzi JL, Gomes ICD. Tópicos em Fonoaudiologia. 1aㅡ ed. São Paulo: Lovise; 1996. p- 493-504.

5. D'Angelis WR. Sistema fonológico do Português: rediscutindo consenso. DELTA. 2008; 18(1): 1-24.

6. Araújo CM, Schneider D, Salles JF, Mota HB, Chelotti VL. Alterações de Fala em escolares e pré-escolares. Revista da Sociedade Brasileira de Fonoaudiologia. 1998; 2(4): 12-5.

7. Patah LK, Takiuchi N. Prevalência das alterações fonológicas e uso dos processos fonológicos em escolares aos 7 anos. Revista CEFAC. 2008; 10(2): 158-67.

8. Vitor RM, Martins CC. Desenvolvimento Fonológico de crianças pré-escolares da Região
Noroeste de Belo Horizonte. Psicologia em Revista. 2007; 13(2): 383-98.

9. GoulartBNG, ChiariBM. Prevalência de desordens de fala em escolares e fatores associados. Revista de Saúde Pública. 2007; 41(5): 726-31.

10. MOTA HB, KESKE-SOARES M, BAGETTI T, CERON MI, MELO FILHA MGC. Análise comparativa da eficiência de três diferentes modelos de terapia fonológica. Pró-Fono Revista de Atualização Científica. 2007; 19(1): 67-74.

11. Pompeu JA. A inserção da criança no mundo letrado na educação infantil. Revista Conteúdo. 2010; 1(3): 103-14.

12. Valente $P$, Ninno CQMS, Avelar RD, Carvente VM. Atuação Fonoaudiológica em Creche de Belo Horizonte: Relato de Experiência. Revista CEFAC. 2006; 8(2): 240-3.

13. BRASIL. Ministério da Saúde. Conselho Nacional de Secretários Municipais de Saúde. O SUS de A a Z: garantindo saúde nos municípios. Brasília: 2005. Editora do Ministério da Saúde; 2009.

14. Luzardo R, Nemr K. Instrumentalização Fonoaudiológica para professores de educação infantil. Revista CEFAC. 2006; 8(3): 289-300.

15. Moura JBVS, Lourinho LA, Valdês MTM, Frota MA, Catrib AMF. Perspectiva da epistemiologia histórica e a escola promotora de saúde. História, Ciências, Saúde- Manguinhos. 2007; 14(2): 489-501.

16. Gonçalves FD, Catrib AMF, Vieira NFC, Vieira LJES. A promoção da saúde na educação infantil. 
Interface-Comunicação, Saúde, Educação. 2008; 12(24): 181-92.

17. Mendonça JE. Ações fonoaudiológicas e promoção da saúde em educação infantil. [Monografia]. Belo Horizonte: Universidade Federal de Minas Gerais- Faculdade de Medicina; 2007.

18. Kramer S, Nunes MF. Gestão Pública, Formação e identidade de profissionais de educação infantil. Cadernos de Pesquisa. 2007; 37(131): 423-54.

19. Vieira LJES, Carneiro RCMM, Frota MA, 1 Gomes ALA, Ximenes LB. Ações e possibilidades de prevenção de acidentes com crianças em creches de Fortaleza, Ceará. Ciência \& Saúde Coletiva. 2009;14(5):1687-97.

20. Altman DG. Pratical statistics for medical research. London: Chapman and Hall; 1991.

21. Caregnato RCA, Mutti, R. Pesquisa qualitativa: análise de discurso versus análise de conteúdo. Texto contexto - enferm. [online]. 2006.15(4): 679-84.

22. Brino RF, Williams LCA. Capacitação do educador acerca do abuso sexual infantil. Interação em Psicologia, 2003;7(2): 1-10.

23. Lofredo-Bonatto MTR, Madureira S. Estudo sobre a percepção e a produção do contraste de vozeamento da fala de crianças de 3 anos. Rev. CEFAC. 2009; 11(1):67-77

24. Wertzner HF, Pagan-Neves LO, Castro MM. Análise acústica e índice de estimulabilidade sons líquidos do português brasileiro. Rev. CEFAC. 2007;9(3):339-50.

25. Keske-Soares M, Mota HB, Pagliarin KC, Ceron MI. Estudo sobre os ambientes favoráveis à produção da líquida não-lateral /r/ no tratamento do desvio fonológico. Revista da Sociedade Brasileira de Fonoaudiologia. 2007;12(1):48-54.

26. Ferrante C, Borsel JV, Pereira MMB. Aquisição fonológica de crianças de classe socioeconômica alta. Rev CEFAC. 2008;10(4): 452-60.

27. Ferrante C, Borsel JV, Pereira MMB. Análise dos processos fonológicos em crianças com desenvolvimento fonológico normal. Rev Soc Bras Fonoaudiol. 2009;14(1):36-40 .

28. Cristófaro-Silva T, Gomes CA. Aquisição fonológica na perspectiva multirepresentacional. Letras de Hoje. 2007;42(1):179-91.

29. Alves RCP, Veríssimo MDLR. Os educadores de creche e o conflito entre cuidar e educar. Revista Brasileira de Crescimento e Desenvolvimento Humano. 2007; 17(1): 13-25.

http://dx.doi.org/10.1590/S1516-18462011005000011

RECEBIDO EM: 07/04/2010

ACEITO EM: 06/09/2010

Endereço para correspondência:

Stela Maris Aguiar Lemos

Av. Prof. Alfredo Balena, $n^{\circ}$ 190, sala 069

Belo Horizonte - MG

CEP: 30100-130

E-mail: smarislemos@medicina.ufmg.br 